\title{
Salivary secretion and connective tissue disease in man
}

\author{
R W MATTHEWS, ${ }^{1}$ K D BHOOLA, ${ }^{2}$ J J RASKER, ${ }^{3}$ M I V JAYSON
}

From the 'Department of Oral Medicine and Oral Surgery, Dental School, Lower Maudlin Street, Bristol BSTO $2 L Y ;{ }^{2}$ Department of Pharmacology, University of Bristol, Medical School, University Walk, Bristol BS $\dot{B}_{-}^{-}$ ITD; ${ }^{3}$ Department of Rheumatology, Vereniging Ziskenzorg, Enschede, Netherlands; and the ${ }^{4}$ Rheumatic Diseases Centre, University of Manchester, Manchester

SUMMARY Parotid and submandibular gland secretions collected from patients with rheumatoid arthritis or systemic sclerosis have been analysed and the results compared with those obtained from a matched group of healthy individuals. Flow rates were measured and the saliva samples assayed for amylase, kallikrein, protein, and salivary $\operatorname{IgA}$ concentration. The results showed that only patients with rheumatoid arthritis had a reduced salivary flow, especially parotid flow, with ã significantly increased concentration of salivary IgA in both parotid and submandibular saliva Patients with systemic sclerosis did not show significantly altered salivary flow rates, but there was a marked depletion of salivary $\operatorname{IgA}$ content in both parotid and submandibular saliva $\vec{\infty}_{\infty}$ Neither disease states appeared to alter the kallikrein or amylase content of saliva. The possible clinical value of these findings is discussed.

Key words: saliva, kallikrein, $\operatorname{IgA}$, amylase, flow.

A complication of connective tissue disease is secretory failure of the lacrimal and salivary glands, which leads to dry eyes and dry mouth. The duct cells of these exocrine glands store kallikrein. ${ }^{12}$ Consequently, measurement of the kallikrein content of saliva could be a sensitive measure of duct damage in patients with connective tissue disease, in which the gland ducts are known to be invaded by lymphocytes and plasma cells.

This study compares the secretion parameters of kallikrein and other compounds in patients who have either rheumatoid arthritis or systemic sclerosis with those obtained from a sex and age matched group of healthy control subjects.

\section{Materials and methods}

Current diagnostic criteria for rheumatoid arthritis ${ }^{3}$ and systemic sclerosis ${ }^{4}$ were used. The study was performed on 20 unselected patients with definite or classical rheumatoid arthritis and 26 unselected patients with systemic sclerosis. Of the 20 rheuma-

Accepted for publication 5 June 1984. Correspondence to $\mathrm{R}$ W Matthews. toid patients 15 were female and five male, and thei름 mean age was 55 years (range $32-70$ years). There were four males and 22 females in the systemie. sclerosis group, and their mean age was 53.5 yearsu (range 26-77 years).

A matching group of 20 healthy subjects no를 taking medications were selected from patient attending the Bristol Dental Hospital for routin treatment.

Subjective assessment of xerostomia. All patients were questioned regarding symptoms of xerostomia The findings are summarised in Table 1. For ethica年 reasons lip gland biopsy was not performed on the systemic sclerosis and rheumatoid patients who did not show xerostomia.

Collections of samples. The use of collection cups or segregators to obtain samples of saliva was nop

Table 1 Number of patients complaining of xerostomia

\begin{tabular}{|c|c|c|}
\hline $\begin{array}{l}\text { Scleroderma } \\
(n=26)\end{array}$ & $\begin{array}{l}\text { Rheumatoid } \\
\text { arthritis } \\
(n=20)\end{array}$ & $\begin{array}{l}\text { Healthy } \\
\text { controls } \\
(n=20)\end{array}$ \\
\hline
\end{tabular}




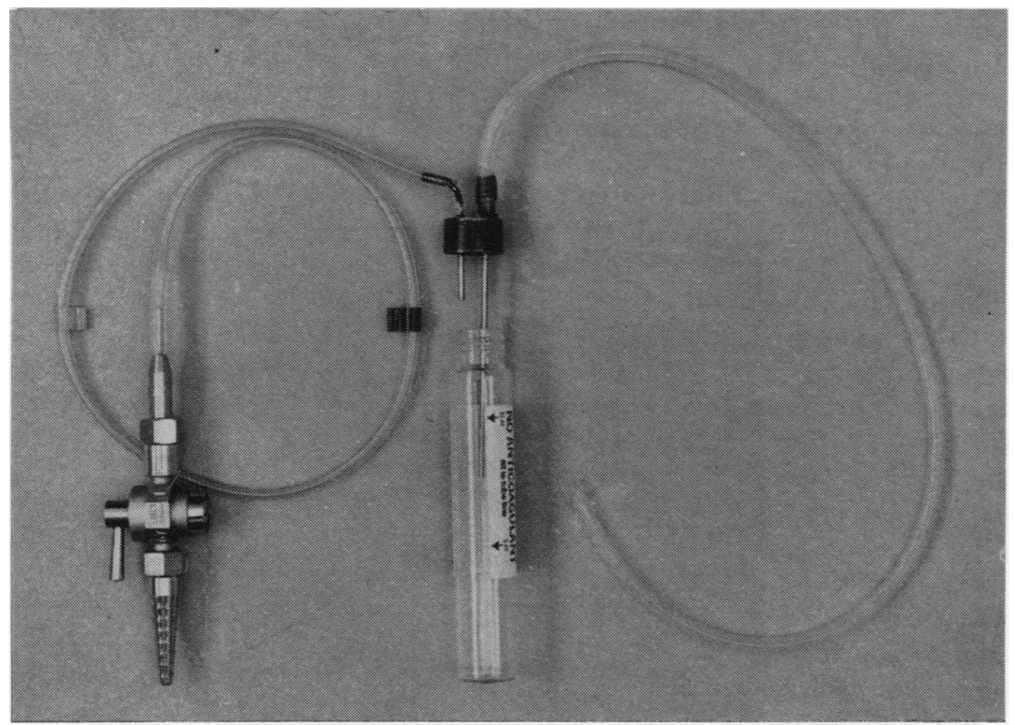

Fig. 1 Apparatus used for collection of saliva.

possible in most of the systemic sclerosis patients owing to the very limited mouth opening associated with the disease. Cannulation of ducts was not feasible in these patients because of the possibility of introducing ascending glandular infection. A simple system for collection of saliva was devised and applied to all the patients studied. The technique used depended upon suction of saliva from the duct orifice into a saliva trap via silicone rubber tube (outer diameter $2.5 \mathrm{~mm}$, Portex Ltd). The suction was obtained from a standard dental aspirator, and the saliva was collected in screw-cap plain blood tubes. The equipment and its method of use are demonstrated in Figs. 1 and 2.

To promote salivary flow $1 \mathrm{ml}$ of $1 \%$ citric acid solution was placed on the tongue, and the saliva collecting time from the right parotid and right submandibular gland duct openings was recorded. Subsequently the saliva volume was measured with pipettes and a microsyringe, from which each salivary flow rate in microlitres per minute was calculated. After each sample was collected the collection apparatus was thoroughly rinsed with distilled water and dried with acetone. A new sample tube was fitted, labelled, and used for the next sample. Collected samples were immediately frozen and stored at $-20^{\circ} \mathrm{C}$ until assayed. All samples were collected between $2 \mathrm{pm}$ and $4 \mathrm{pm}$.

Assay techniques. Protein was determined by the method of Lowry et al. ${ }^{6}$

Kallikrein (EC 3.4.21.8, formerly EC 3.4.4.21) was assayed by the enzyme ethanol method ${ }^{7}$ with benzoyl-L-arginine ethyl ester as substrate. The assay medium $(3.0 \mathrm{ml})$ for measuring kallikrein activity contained $2 \mathrm{mmol}$ of benzoyl-L-arginine ethyl ester, $1 \mathrm{mmol}$ of nicotinamide-adenine

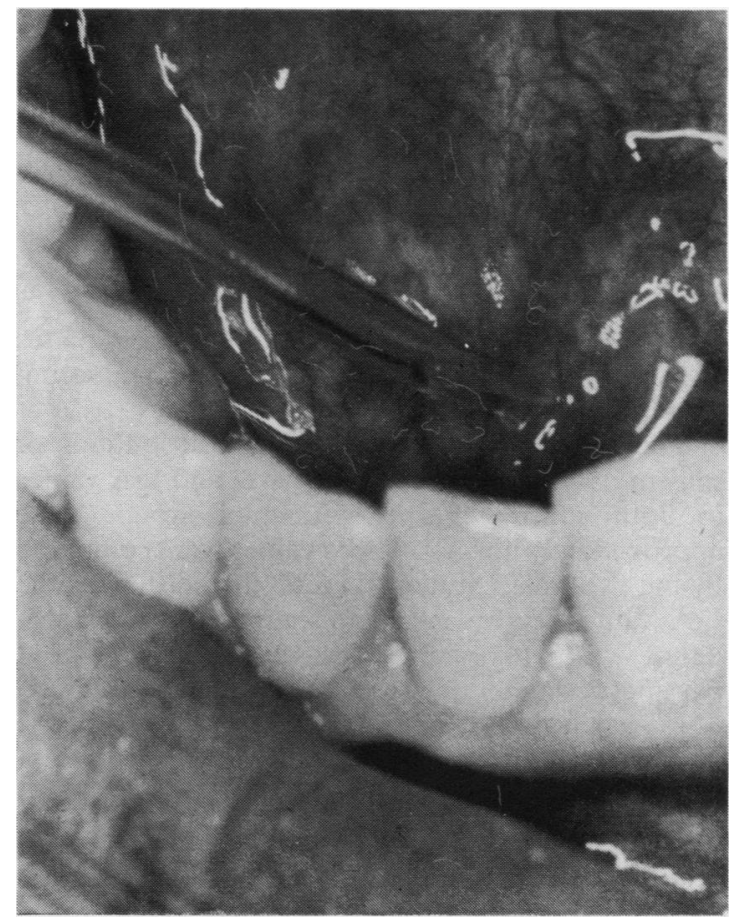

Fig. 2 Collecting saliva from the right submandibular duct. 
nucleotide $/ \mathrm{l}, 0.167 \mathrm{mg}$ of yeast alcohol dehydrogenase '(EC 1.1.1.71; Boehringer)/ml, and $2.7 \mathrm{ml}$ of buffer solution $(150 \mathrm{mmol}$ of semicarbazide hydròchloride, $150 \mathrm{mmol}$ of tetrasodium pyrophosphate/l, and $2 \mathrm{mmol}$ of glycine/l, $\mathrm{pH}$ adjusted to 8.3 with $\mathrm{NaOH}, 2 \mathrm{~mol} / \mathrm{l}$ solution). The rate of hydrolysis of benzoyl-L-arginine ethyl ester at $366 \mathrm{~nm}$ was followed for $3 \mathrm{~min}$ at $25^{\circ} \mathrm{C}$ in a PyeUnicam SP 1800 recording spectrophotometer. The change in absorbance per minute $\left(\times 10^{3}\right)$ was used to express kallikrein activity as units/mg protein.

Amylase (EC 3.2.1.1.) activity was assayed by a modification of the dinitrosalicylate method. ${ }^{8}$ The dinitrosalicylate reagent was prepared by dissolving $10 \mathrm{~g}$ of 3,4,-dinitrosalicylic acid, $16 \mathrm{~g}$ of $\mathrm{NaOH}$, and $300 \mathrm{~g}$ of potassium sodium tartrate in deionised distilled water. The starch solution $(30 \mathrm{mg} / \mathrm{ml})$ and the maltose standard $(10 \mathrm{mg} / \mathrm{ml}$ in $5 \mathrm{mmol} / \mathrm{l}$ Sorensen's buffer, pH 6.9) were also freshly prepared. For each assay, reagent blank, standard, and sample tubes were prepared in duplicate. Each tube contained $50 \mu \mathrm{l}$ of starch solution, $50 \mu \mathrm{l}$ of buffer, and either $50 \mu \mathrm{l}$ of distilled water or $50 \mu \mathrm{l}$ of an appropriate dilution of standard or $50 \mu \mathrm{l}$ of saliva sample. After 3 min incubation at $25^{\circ} \mathrm{C}, 100 \mu$ lof dinitrosalicylic acid reagent was added, and the tubes were heated for $10 \mathrm{~min}$ at $100^{\circ} \mathrm{C}$ to allow development of the chromophore. Cold distilled water $(3 \mathrm{ml} /$ tube $)$ was then added, and the tubes were placed on ice for $30 \mathrm{~min}$. The standards and samples were read against the reagent blank in a Pye-Unicam SP 500 at $530 \mathrm{~nm}$, and amylase activity was expressed as $\mathrm{mg}$ maltose per $\mathrm{mg}$ salivary protein.

Measurement of secretory immunoglobulin A (IgA) was performed by radial immunodiffusion ${ }^{9} 10$ using Behring Tri-partigen immunodiffusion plates (Hoechst Pharmaceuticals Ltd) and human serum standards.

Statistical analysis of data. The distributions of salivary flow rate, protein, amylase, and IgA values in both control and experimental groups were approximately normal. These values were compared by the two-tailed Student's $t$ test. In addition, as the IgA values were somewhat skewed, it was considered wise to analyse these results by nonparametric methods too. The Mann-Whitney U test $^{11}$ was used, to examine the IgA results but the conclusions were no different from those of Student's $t$ test.

\section{Results}

Table 1 shows the results of the subjective assessment of xerostomia in the patients studied. Only six of the 20 healthy controls $(30 \%)$ gave responses suggestive of xerostomia, whereas 13 of the $2 \sqrt{6}$ systemic sclerosis patients $(50 \%)$ and 15 of the 28 rheumatoid patients $(75 \%)$ were scored as having symptoms of xerostomia.

Figs. 3a-e show the scatter diagrams of the value for salivary flow, protein, kallikrein, amylase, an की IgA. The bars show the median values and the means and standard errors are given below the figures.

The following results were significantly differen from the corresponding values of saliva from health controls.

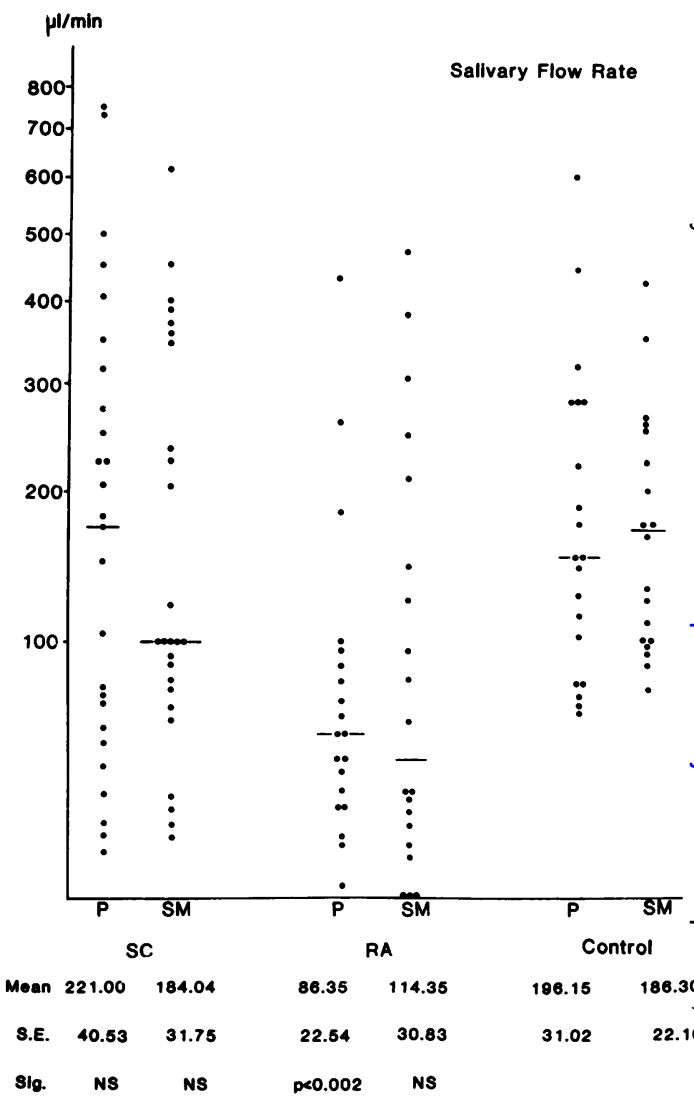

Fig. 3a

Fig. 3 The results of (a) salivary flow rate, (b) protein, (c) amylase, (d) kallikrein and (e) IgA estimations are summarised in the diagrams. Means and standard errors with their significance are shown at the base of each chart. $\mathrm{P}=$ Parotid gland. $\mathrm{SM}=$ Submandibular gland. $\mathrm{SC}=$ Scleroderma $. \mathrm{RA}=$ Rheumatoid arthritis. $\mathrm{SE}=$ Standard error. Sig. $=$ Significance. $\mathrm{NS}=$ Not significant . 


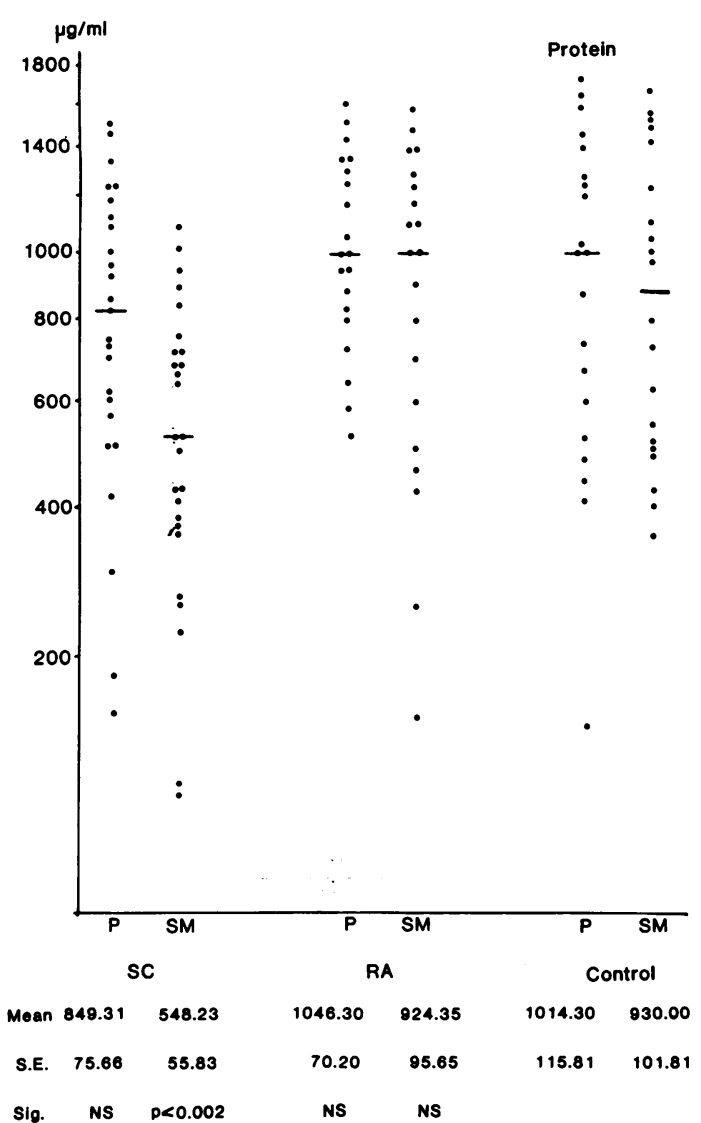

Fig. 3b

\section{Rheumatoid arthritis}

1. Reduced parotid gland salivary flow $(p<0.002)$.

2. Elevated IgA content of both parotid $(p<0.001)$ and submandibular $(\mathrm{p}<0.001)$ gland saliva.

\section{Systemic sclerosis}

1. Decreased total protein content of submandibular saliva $(p<0.002)$.

2. Decreased IgA content of both parotid $(p<0.01)$ and submandibular $(\mathrm{p}<0.001)$ gland saliva.

\section{Discussion}

Assessment of salivary gland function in connective tissue disease is well established. Reduced stimulated parotid salivary flow rate has been found to be the most sensitive index of salivary gland dysfunction in Sjögren's syndrome, followed by labial gland biopsy and sialography. ${ }^{12}$

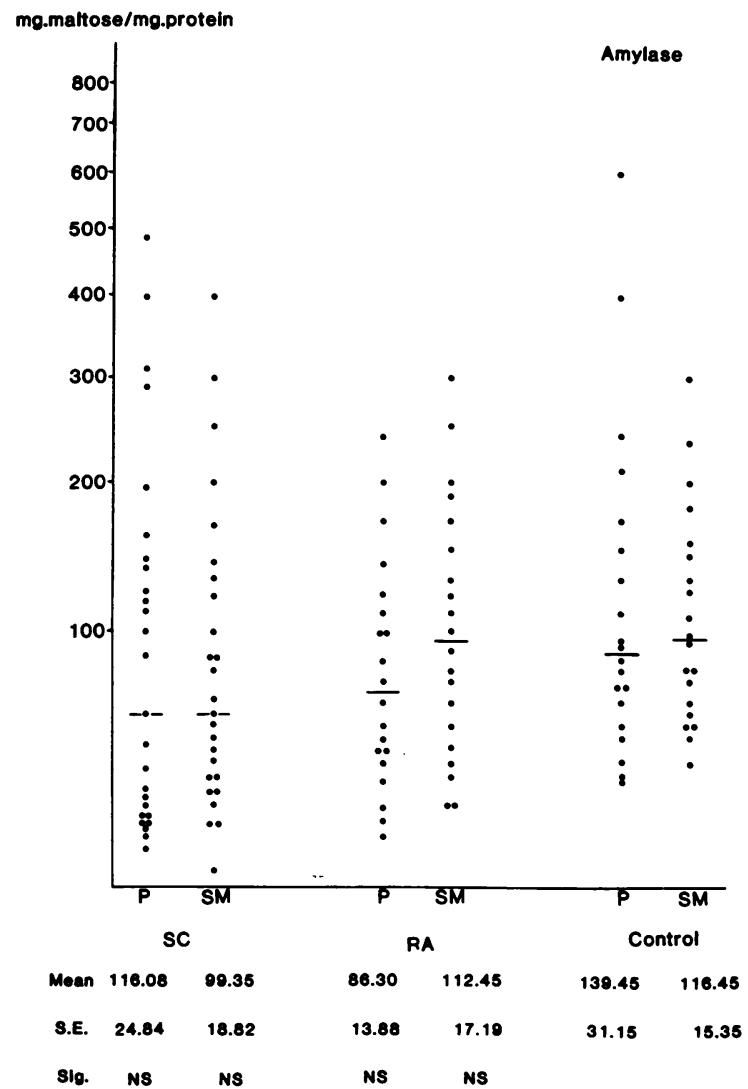

Fig. 3c

As deficient quantity and quality of saliva is the direct cause of symptoms, measurement of both has importance in this study. Flow rate estimations from the parotid and submandibular glands has the disadvantage of examining secretions from only one group of glands and ignores the significant contributions made by the minor glands. The amount of saliva collected is influenced by many factors including age, sex, time of day, size of secreting gland, and the technique of saliva collection.

The method of collection for this study was designed to overcome access difficulties encountered in the systemic sclerosis patients who had very limited mouth opening due to the nature of their disease. Parotid saliva was relatively easier to collect than submandibular saliva using the described technique and it is likely that not every fraction of a millilitre was collected from a duct opening during the timed period. However, the results of salivary flow rate from the parotid gland of healthy subjects 


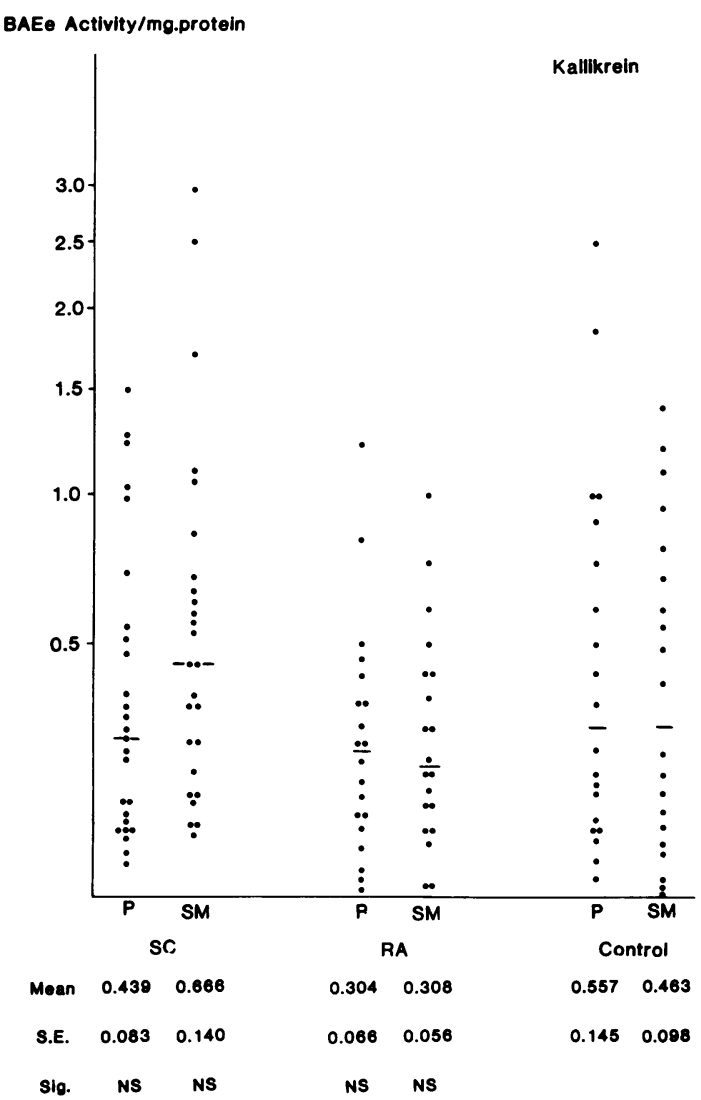

Fig. 3d

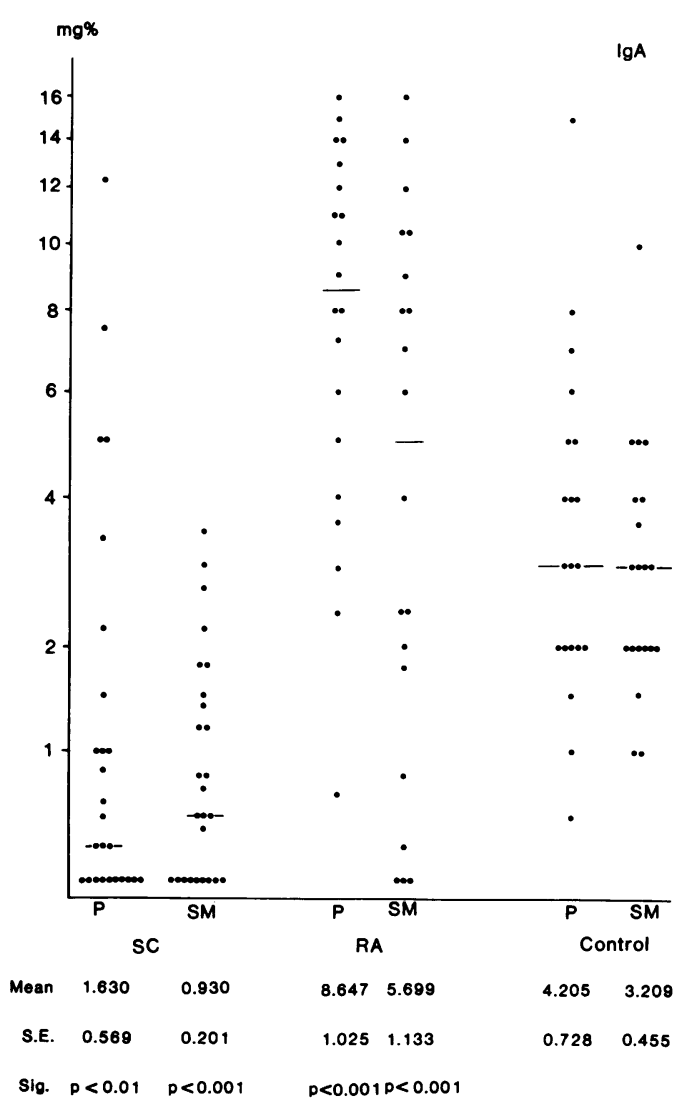

Fig. 3e following $1 \%$ citric acid stimulation compares well with published values obtained by standard techniques. $^{1314} 1 \%$ citric acid was chosen as the salivary gustatory stimulant because in a previous investigation of hormonal influence on kallikrein secretion $^{15}$ this was the method used.

The scatter of values found in this study for each of the variables examined in diseased and healthy subjects was wide, making it difficult to obtain a predictive value which would characterise a particular disease state. It is clear that estimations of flow rate or composition have to be interpreted along with other investigations to make a definitive diagnosis. It has been pointed out ${ }^{16}$ that results from different sialometric methods are not comparable because of great individual variations. The same caution must apply to interpretation of analytical values of discrete compounds in saliva such as amylase, kallikrein, and protein.
The only finding in this study which can bes directly related to a disease state is a markedlye depleted salivary IgA level in parotid or submano dibular saliva of systemic sclerosis patients. The serum IgA levels of all these patients was normalo Thus a depleted salivary $\operatorname{IgA}$ level in a patien suspected of having scleroderma would tend to be confirmatory. Further, a patient who has systemic sclerosis and an elevated IgA level in saliva may

require further assessment.
The finding that rheumatoid patients have ele vated $\operatorname{IgA}$ in both parotid and submandibular salivक्ष is at variance with other reports, ${ }^{17}$ where no? detectable differences in salivary $\operatorname{IgA}$ were found ino a study of 12 female patients with Sjögren's syn-0 drome. Others ${ }^{18}$ found a decreased IgA content in parotid saliva in three out of five patients with Sjögren's syndrome. However, immunological assayo techniques have advanced considerably in recent 
years, and the larger number of patients screened in this study makes the present findings relevant, and is in accordance with more recent observations. ${ }^{19}$

A study on whole saliva ${ }^{20}$ as well as a study on separate parotid and submandibular saliva ${ }^{21}$ showed that salivary flow and IgA content have an inverse relationship, that is, as salivary flow increases the salivary IgA falls. However, it does not follow that a raised $\operatorname{IgA}$ would be expected in saliva from patients with reduced salivary flow. It could be that in immunologically damaged glands of patients with rheumatoid arthritis the transport and secretion mechanism of $\operatorname{IgA}$ is intact, whereas in the damaged glands of patients with systemic sclerosis it is not.

Both amylase and kallikrein levels in saliva showed no significant changes in rheumatoid arthritis or systemic sclerosis. As the majority of patients were female and postmenopausal, any possible hormonal effect on kallikrein secretion was thought to be small, especially as the samples were collected in the afternoon when the female hormone effect is minimal. ${ }^{15}$

Since the total protein in submandibular saliva of systemic sclerosis patients was significantly reduced, and there was no change in the kallikrein or amylase level of the same saliva, it seems that it is the $\operatorname{IgA}$ which is preferentially depleted from saliva in systemic sclerosis. The mechanism of this selectivity is unknown.

Parotid salivary flow rates measured in this study were significantly reduced in those patients with rheumatoid arthritis, and this confirms previous findings. ${ }^{12}$ The lack of significant decrease in salivary flow from parotid or submandibular glands of patients with systemic sclerosis is at variance with other reports. ${ }^{22-26}$ It is possible that exocrine gland failure in systemic sclerosis, when it occurs, is primarily due to fibrosis and collagen deposition within the glands rather than immune inflammatory damage such as occurs in rheumatoid arthritis and that the latter causes earlier gland damage. Subjective assessment of xerostomia showed that patients with systemic sclerosis were more likely to have symptoms of dry mouth than controls but not so frequently as patients with rheumatoid arthritis. In the latter group the symptoms were confirmed as being related to deficiency of salivary flow, but in the systemic sclerosis group such a relationship was not confirmed statistically.

Therefore this study has shown that patients with systemic sclerosis have a significantly reduced salivary $\operatorname{IgA}$ level as estimated from human serum as standard, and rheumatoid patients were found to have a significantly increased salivary IgA level. This may provide a useful clinical test when investigating patients with connective tissue disease.
It has also been shown that there is no consistent link between systemic sclerosis and deficiency of salivary flow, though symptoms of dry mouth may be present. Further, no significant alteration in the secretion of amylase or kallikrein is attributable to either connective tissue disease.

Our theory that salivary kallikrein estimations might be a sensitive index of gland duct damage associated with connective tissue disease has not been confirmed. It appears that gland damage and kallikrein secretion fall in parallel, with salivary concentration being kept relatively constant.

We thank Professor A I Darling and Professor C M Scully for their valuable advice with this study. Mr N Fathers produced the photographic material and Mrs Stella Sage gave technical assistance. Financial support from the Medical Research Council is gratefully acknowledged.

\section{References}

1 Schachter M, Peret M W, Moriwaki C, Rodrigues J A A. Localisation of kallikrein in submandibular gland of cat. guinea-pig, dog and man by the immunoperoxidase method. $J$ Histochem Cytochem 1980; 28: 1295-300.

2 Schachter M. Wheeler G D. Matthews R W. Peret M W, Moriwaki C. Ultrastructural immuno-localisation of kallikrein in apical granules of striated duct cells of cat submandibular gland. J Histochem Cytochem 1983; 31: 345-7.

3 Ropes M W, Bennett G A, Cobb S, Jacox R, Jessar R. Revision of diagnostic criteria for rheumatoid arthritis. Bull Rheum Dis 1985; 9: 175-6.

4 Masi A T, Medsger T A. Rodnan G P, et al. Methods and preliminary results of the Scleroderma Criteria Co-operative Study of the American Rheumatism Association. Clin Rheum Dis 1979; 5: 27-48.

5 Carlson A J, Crittenden A Z. The relation of ptyalin concentrations to the diet and rate of secretion. Am J Physiol 1910; 26: 169.

6 Lowry O H, Rosebrough N J, Farr A L. Randall R J. Protein measurement with Folin phenol reagent. J Biol Chem 1951; 193: $265-75$.

7 Trautschold I, Werle E. Spektrophotometrische bestimmung des Kallikreins und seiner Inaktivatoren. Hoppe Seylers $Z$ Physiol Chem 1961; 325: 48-59.

8 Dahlquist A. A method for the determination of amylase in intestinal content. Scand J Clin Lab Invest 1962; 14: 145-51.

9 Mancini G, Carbonara A O. Heremans J F. Immunochemical quantitation of antigens by single radial immunodiffusion. Immunochemistry 1965; 2: 235-8.

10 Khayam-Bashi H, Slaughter S, Blanken R M. Quantitative estimation of secretory immunoglobulin- $A$ by radial immunodiffusion technique. Clin Chim Acta 1976; 66: 63-7.

11 Siegel S. Non-parametric statistics for the behavioural sciences. Tokyo: McGraw-Hill, Kogaskusha, 1956.

12 Chisholm D M. Mason D K. Salivary gland function in Sjögren's syndrome-a review. Br Dent J 1973; 135: 393-9.

13 Shannon I L. Reference table for human parotid saliva collected at various levels of exogenous stimulation. J Dent Res 1973; 52: 1157.

14 Mason D K. Chisholm D M. Salivary glands in health and disease. London: Saunders, 1975.

15 Bhoola K D, Matthews R W, Roberts F. A survey of salivary kallikrein and amylase in a population of schoolgirls, throughout the menstrual cycle. Clin Sci Mol Med 1978; 55: 561-5. 
16 Ericson S. An investigation of human parotid saliva secretion rate in response to different types of stimulation. Arch Oral Biol 1969; 14: 591-3.

17 Bluestone R, Gumpel J M, Goldberg L S, Holborow E J. Salivary immunoglobulins in Sjögren's syndrome. Int Arch Allergy 1972; 42: 686-92.

18 Rougier J, Druand L, Creyssel R, Chazot G. Dosages des immunoglobulins dans la saliva parotidienne interet dans le diagnostic precoce du syndrome de Gougerot-Sjögren. Bull Soc Ophtalmol Fr 1972; 72: 1049-54.

19 Speilman A, Ben-Aryeh H. Lichtig C, et al. Correlation between sialochemistry and lip biopsy in Sjögren's syndrome patients. Int J Oral Surg 1982; 11: 326-30.

20 Gronblad E A. Concentration of immune-globulins in human whole saliva: effect of physiological stimulation. Acta Odontol Scand 1982; 40: 87-95.
21 Mandel I D, Khurana H S. The relation of human salivary. A globulin and albumin to flow rate. Arch Oral Biol 1969; 14 1433-5.

22 Shearn M A. Sjögren's syndrome in association with scleroder ma. Ann Intern Med 1960; 52: 1352-62.

23 Shearn M A. Sjögren's syndrome. London: Saunders, $1976 \frac{\bar{\Phi}}{\bar{D}}$

24 Camus J P. Emerit J. Reinert P. Gullien P. Crouzet J. Fourotฉ Sclérodermic familiale avec syndrome de Sjögren et anomalic@ lymphocytaires et chromosomiques. Ann Med Interne (Paris $)^{s}$ 1970; 121: 149-61.

25 Goel K M, Shanks R A. Scleroderma in childhood. A report of 5 cases. Arch Dis Child 1974: 49: 861-6.

26 Cipoletti J F, Buckingham R B, Barnes L, et al. Sjögren syndrome in progressive systemic sclerosis. Ann Intern Me 1977; 87: 535-41. 